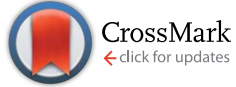

Cite this: Chem. Sci., 2017, 8, 606

Received 29th June 2016

Accepted 2nd September 2016

DOI: $10.1039 / \mathrm{c} 6 \mathrm{sc} 02878 \mathrm{k}$

www.rsc.org/chemicalscience

\section{Enantioselective bifunctional iminophosphorane catalyzed sulfa-Michael addition of alkyl thiols to unactivated $\beta$-substituted $-\alpha, \beta$-unsaturated esters $\dagger$}

\begin{abstract}
Jinchao Yang, Alistair J. M. Farley and Darren J. Dixon*
The highly enantioselective sulfa-Michael addition of alkyl thiols to unactivated $\beta$-substituted- $\alpha, \beta$ unsaturated esters catalyzed by a bifunctional iminophosphorane (BIMP) organocatalyst is described. The low acidity of the alkyl thiol pro-nucleophiles is overcome by the high Brønsted basicity of the catalyst and the chiral scaffold/thiourea hydrogen-bond donor moiety provides the required enantiofacial discrimination in the addition step. The reaction is broad in scope with respect to the alkyl thiol and $\beta$-substituent of the $\alpha, \beta$-unsaturated ester, affords sulfa-Michael adducts in excellent yields (up to $>99 \%$ ) and enantioselectivity (up to $97: 3$ er) and can operate down to 1 mol\% catalyst loading.
\end{abstract}

Unactivated $\beta$-substituted- $\alpha, \beta$-unsaturated esters, such as methyl crotonate, methyl cinnamate and their homologues, are a class of low reactivity electrophiles that offer a wealth of untapped potential in the field of enantioselective organocatalysis. ${ }^{1}$ To date, these esters have remained a persistent challenge as Michael acceptors in asymmetric catalysis using both metal-rich and metal-free catalyst systems, largely due to their low inherent electrophilicity ${ }^{2}$ and low propensity for catalyst activation and enantioface discrimination. ${ }^{3,4}$ They are commercial and cheap, or are readily prepared by a variety of standard methods and are stable. In contrast to commonly used (reactive) Michael acceptors such as nitroolefins, they lie at the bottom of the Mayr electrophile reactivity $(E)$ scale, $^{5,6}$ and unlike enal and enone Michael acceptors they cannot be activated through iminium ion formation with chiral amine catalysts. $^{7}$ Related literature examples employ activated carboxylic derivatives ${ }^{8}$ such as $\mathrm{N}$-enoyl imides, $\mathrm{N}$-enoyl oxazolidinones, perfluorinated alkyl esters, thioamides, $N$-enoyl pyrroles and, most recently, aryl esters. ${ }^{9}$ Alternatively, activating substituents at the $\alpha$ - or $\beta$-positions can also be used to gain reactivity and/or stereoselectivity. To illustrate the case in point, to date there has not been a single report of a highly enantioselective addition of a pro-nucleophilic reagent [a carbon-centered $(\mathrm{C}-\mathrm{H})$ or heteroatom-centered $(\mathrm{X}-\mathrm{H})$ acid] to unactivated alkyl cinnamate or crotonate esters under organocatalytic conditions. ${ }^{10}$ Effectively, these cheap chemical feedstocks are out of reach of existing chiral organocatalysts and accordingly are a very attractive 'simple' target class of

Department of Chemistry, Chemistry Research Laboratory, University of Oxford, 12 Mansfield Road, Oxford, UK. E-mail: Darren.dixon@chem.ox.ac.uk

$\dagger$ Electronic supplementary information (ESI) available: Experimental procedures, spectroscopic data, copies of ${ }^{1} \mathrm{H}$ and ${ }^{13} \mathrm{C}$ NMR spectra and HPLC and GC chromatograms. See DOI: 10.1039/c6sc02878k electrophiles for new enantioselective organocatalytic reaction development (Fig. 1).

A proven strategy to overcome low substrate electrophilicity in base-catalyzed polar addition reactions is to increase the concentration of the nucleophilic conjugate base in the pot - and therefore the rate of the nucleophilic addition reaction - by enhancing the Brønsted basicity of the catalyst relative to tertiary amine catalysts. ${ }^{11-13}$ To this end, we disclosed that bifunctional iminophosphorane (BIMP) catalysts, containing a novel organosuperbase were highly efficacious in the first general enantioselective organocatalytic ketimine nitro-Mannich reaction. ${ }^{\mathbf{1 2 b}, \boldsymbol{d}}$ Likewise, very recently, high catalyst performance (in terms of

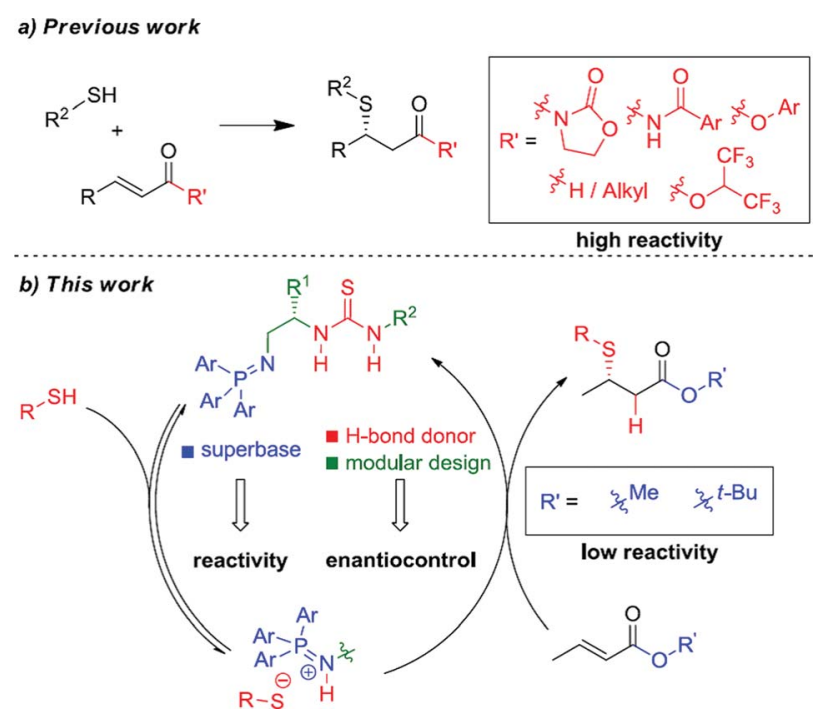

Fig. 1 Bifunctional Brønsted base/H-bond donor organocatalytic SMA to $\alpha, \beta$-unsaturated ester derivatives. 
reactivity and enantioselectivity) with a second generation BIMP catalyst was also witnessed in the first organocatalytic conjugate addition of alkyl thiols to unactivated $\alpha$-substituted acrylate esters (such as methyl methacrylate). ${ }^{12 e}$ In both of these transformations an organosuperbase was demonstrated to be essential for reactivity.

We speculated that the reluctance of unactivated $\beta$-substituted- $\alpha, \beta$-unsaturated esters to undergo organocatalytic Michael addition reactions could be overcome using our BIMP catalyst family. To exemplify this we chose the sulfa-Michael addition (SMA) of alkyl thiols as this is a reaction of central importance for the asymmetric construction of chiral sulfides possessing a stereogenic centre at the $\beta$-carbon and no organocatalytic enantioselective version has previously been reported..$^{14,15}$ We reasoned that the high Brønsted basicity of our BIMP catalysts could activate the high $\mathrm{p} K_{\mathrm{a}}$ alkyl thiol pronucleophile $\left(\mathrm{p} K_{\mathrm{a} \text { (DMSO) }}=17 \text { for } n \text {-BuSH) }\right)^{16,17}$ and the modular design of the catalyst family, through its variable backbone scaffold, hydrogen-bond donor group and iminophosphorane superbase would expedite optimal catalyst identification. Herein, and as part of our research program towards the development of novel asymmetric reactions with challenging electrophile/pro-nucleophile combinations, we wish to report our investigations leading to the highly enantioselective SMA reaction of alkyl thiols to unactivated $\beta$-substituted- $\alpha, \beta$-unsaturated esters.

We chose commercially available methyl crotonate (2a) and 1-propanethiol (3a) as our model system and investigated reactivity using first generation BIMP catalyst 1a (Table 1, entry 1). In toluene, at room temperature using $10 \mathrm{~mol} \%$ catalyst we were delighted to observe an exceptional reactivity profile; $\beta$ mercaptoester product $4 \mathbf{a}$ was afforded in near quantitative yield after only 2 hours with low but significant enantiocontrol $(55: 45 \mathrm{er}){ }^{18}$ With good reactivity established we next investigated the performance of a small library of second generation BIMP catalysts featuring variations around the amide-thiourea motif that we recently reported ${ }^{12 e}$ (Table 1 , entries 2-6). The modular design of our BIMP catalysts allowed rapid library<smiles>CC(C)(C)C(CN=CPN)NC(=S)Nc1cc(C(F)(F)F)cc(C(F)(F)F)c1</smiles>

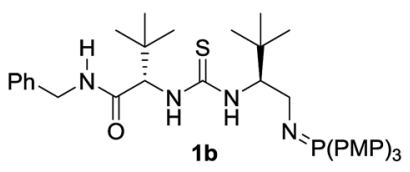<smiles>CC(C)(C)C(NC(=O)NC(C(CN=CPN)C(C)(C)C)C(C)(C)C)C(=O)N(Cc1ccccc1)Cc1ccccc1</smiles>
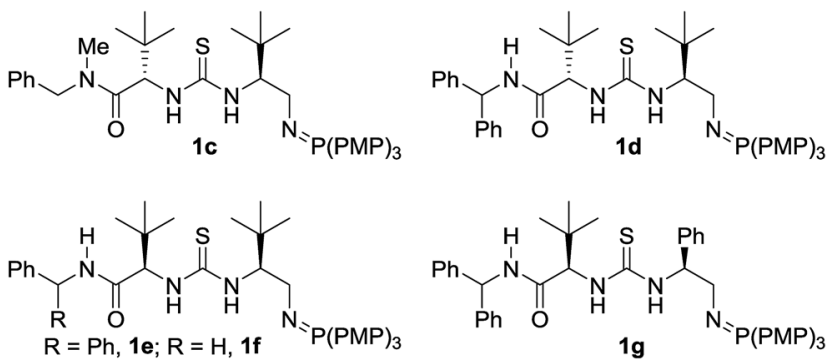

Fig. 2 Bifunctional iminophosphorane (BIMP) organocatalysts used in the optimization of the SMA reaction. PMP $=p$-methoxyphenyl.
Table 1 Catalyst screening studies and reaction optimization ${ }^{a}$

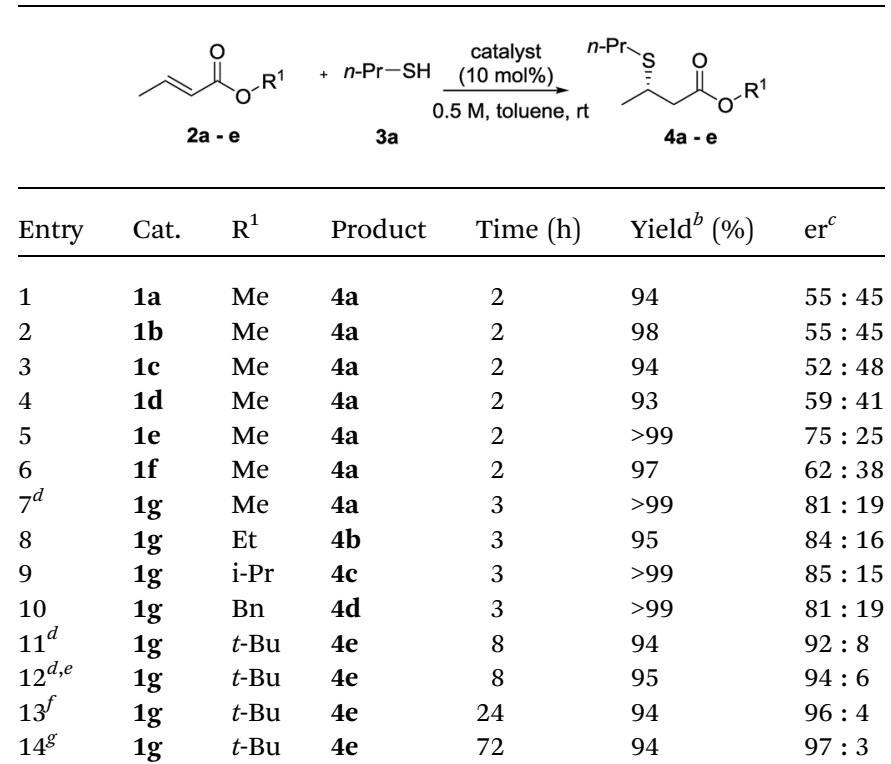

${ }^{a}$ Reactions were carried out with $0.20 \mathrm{mmol}$ of 2 and $0.60 \mathrm{mmol}$ of 3 a. ${ }^{b}$ Isolated yield. ${ }^{c}$ Determined by HPLC analysis on a chiral stationary phase. ${ }^{d}$ Reaction performed on $0.10 \mathrm{mmol}$ scale of 2a. ${ }^{e}$ Reaction performed at $0{ }^{\circ} \mathrm{C} .{ }^{f}$ Reaction performed at $0{ }^{\circ} \mathrm{C}$ in $\mathrm{Et}_{2} \mathrm{O} .{ }^{g}$ Reaction performed at $-15{ }^{\circ} \mathrm{C}$ in $\mathrm{Et}_{2} \mathrm{O}$.

generation and our attention focussed on the amide-thiourea moiety as the H-bond donor group and the tris-(4-methoxyphenylphosphine) derived iminophosphorane as the Brønsted basic group (Fig. 2).

Catalysts 1b-d possessing a thiourea constructed from two (S)-configured tert-leucine derived residues, the tris-(4-methoxyphenylphosphine)-derived iminophosphorane and a variable terminal amide group gave poor enantioselectivity in all cases (Table 1, entries 2, 3, and 4). When catalyst $1 \mathbf{e}$ - the diastereomer of 1d - was trialled however, a significant boost to the enantioselectivity was witnessed (Table 1 , entry $5,75: 25$ er). ${ }^{19}$

A comparison with an analogous catalyst possessing a phenylglycine and a tert-leucine residue (19) resulted in a slight improvement to the enantioselectivity (Table 1 , entry 7, $81: 19$ er). At this stage, the effect of varying the ester group of the crotonate on the enantioselectivity in the SMA was investigated. A range of simple, commercial or readily synthesized alkyl crotonate esters were trialled and a correlation between the size of the ester group and the enantioselectivity was observed pleasingly tert-butyl crotonate (2e) afforded the product $4 \mathbf{e}$ in $92: 8$ er albeit in a slightly increased reaction time of $8 \mathrm{~h}$ (Table 1, entry 11). A reoptimization of the reaction conditions to $0.5 \mathrm{M}$ in $\mathrm{Et}_{2} \mathrm{O}$ at $0{ }^{\circ} \mathrm{C}$ (Table 1, entries $12 \& 13$ and ESI $\dagger$ ) resulted in a significant boost to the enantioselectivity $(96: 4$ er) and cooling the reaction temperature further to $-15{ }^{\circ} \mathrm{C}$ afforded $\beta$-mercaptoester 4e in 94\% yield and $97: 3$ er (Table 1, entry 14 ).

With optimized reaction conditions established, the scope of the transformation with respect to the thiol pro-nucleophile and the $\alpha, \beta$-unsaturated ester was investigated (Fig. 3). Minimal variation to the enantioselectivity was observed across a good range of linear (propyl to decyl) or branched (cyclic and acyclic) 


$$
\overbrace{2 e-m}^{O_{O}^{t} B u}
$$

$4 e, 94 \%$ yield $^{a}$ 97:3 er<smiles>CCCCC(C)CC(=O)OC[As]C</smiles>

$4 \mathbf{4 i}, 97 \%$ yield 95:5 er<smiles>CCCCOC(=O)C[C@H](C)S[R16](C)(C)C</smiles>

$4 \mathrm{~m}, 99 \%$ yield $^{\mathrm{a}}$ 95:5 er<smiles>C=CCCC(CC(=O)OCCC)SCCC</smiles>

4q, $84 \%$ yield 94:6 er

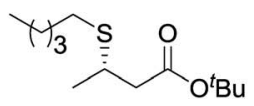

4f, $98 \%$ yield 95:5 er

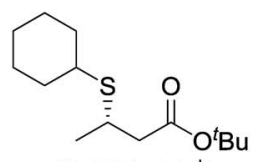

$4 j, 68 \%$ yield $^{b}$ 95:5 er<smiles></smiles>

4n, $98 \%$ yield $^{c}$ $88: 12$ er<smiles>CCCS[C@H](CCc1ccccc1)CC(=O)O[Ga]O[Ge]</smiles>
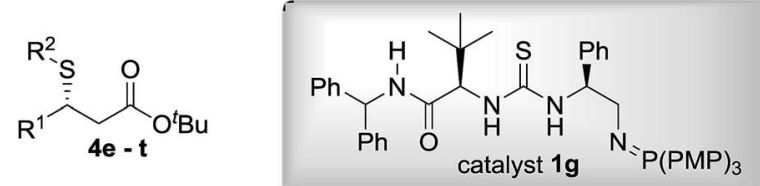

Fig. 3 Scope of the SMA of alkyl thiols to $\beta$-substituted- $\alpha, \beta$-unsaturated esters. Reactions were carried out with $0.20 \mathrm{mmol} 2$ and $0.60 \mathrm{mmol} 3$. Yields are isolated yields and enantiomeric ratios were determined by HPLC analysis or GC analysis on a chiral stationary phase. ${ }^{a}$ The reaction was performed at $-15{ }^{\circ} \mathrm{C}$. ${ }^{b}$ The reaction was quenched after $96 \mathrm{~h}$. ${ }^{C}$ Absolute configuration of $4 \mathrm{n}$ determined by chemical correlation (see ESI $\dagger$ ).

alkyl mercaptans. The reaction with 4-methoxybenzyl mercaptan was also well-tolerated and afforded the $\beta$-mercaptoester $\mathbf{4 m}$ in $99 \%$ yield and $95: 5 \mathrm{er}$ at $-15{ }^{\circ} \mathrm{C}$.

Following investigation into the scope of the reaction with respect to the alkyl thiol, variation to the $\beta$-substituent of the $\alpha, \beta$-unsaturated ester was subsequently examined using 1-propanethiol or 4-methoxybenzyl mercaptan as the sulfur-centred pro-nucleophile. We were pleased to observe that the excellent reactivity and selectivities were maintained when tert-butyl cinnamate, bearing a phenyl group at the $\beta$-position, was used as the electrophile to afford the desired $\beta$-mercaptoester $4 \mathbf{n}$ in $98 \%$ yield and $88: 12$ er.

Similarly, excellent yields of the $\beta$-mercaptoesters 4o-r were obtained from the corresponding primary alkyl $\beta$-substituted$\alpha, \beta$-unsaturated esters with very good levels of enantiocontrol. $\beta$-Mercaptoesters $4 \mathbf{s}$ and 4 t containing a terminal $N$-Boc protected amine and TBS protected hydroxyl group respectively

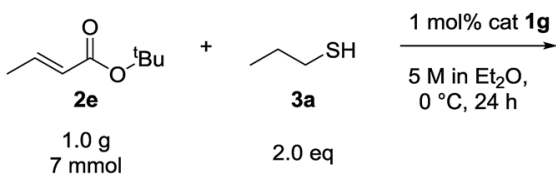

Scheme 1 Preparative scale synthesis of $4 \mathrm{e}$. were also synthesized in good to excellent yields and excellent enantiomeric ratios.

Although the scope of the reaction was performed with 10 mol\% catalyst loading, we were keen to demonstrate lower loadings were viable. Accordingly, and after reoptimization of the reaction conditions, to $5 \mathrm{M}$ in $\mathrm{Et}_{2} \mathrm{O}$ at $0{ }^{\circ} \mathrm{C}$, we were pleased to find $\beta$-mercaptoester $4 \mathbf{e}$ was afforded in near quantitative yield and 95 : 6 er on $7 \mathrm{mmol}$ scale of tert-butyl crotonate (2e) using $1 \mathrm{~mol} \%$ catalyst $1 \mathrm{~g}$ (Scheme 1).

To demonstrate synthetic utility of the $\beta$-mercaptoester products a selection of standard chemical transformations were carried out (Scheme 2). Thus $\beta$-mercaptoester 4e (95: 5 er) was transesterified to the methyl ester $\mathbf{4 a}$ in a two step process;

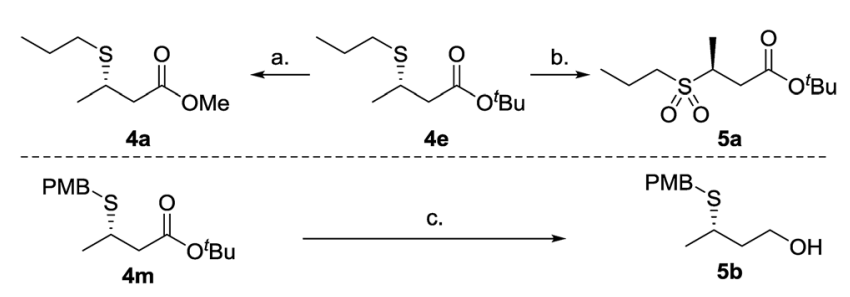

Scheme 2 Derivatization. (a) TFA, $\mathrm{Et}_{2} \mathrm{O}, 0^{\circ} \mathrm{C}$ to rt, then $\mathrm{SOCl}_{2}, \mathrm{MeOH}$, $0{ }^{\circ} \mathrm{C}$ to rt, $78 \%$ yield over two steps, $94: 6$ er. (b) $m$-CPBA, $\mathrm{CH}_{2} \mathrm{Cl}_{2}$, $0{ }^{\circ} \mathrm{C}, 2 \mathrm{~h}, 96 \%$ yield, $94: 6 \mathrm{er}$. (c) DIBAL-H, THF, $-60{ }^{\circ} \mathrm{C}, 2 \mathrm{~h}, 93 \%$ yield, $93: 7 \mathrm{er}$. 
initial acidic cleavage of the tert-butyl ester and subsequent methyl ester formation under acidic conditions afforded $4 a$ in $78 \%$ yield without compromising stereochemical integrity. Oxidation of $4 \mathbf{e}$ afforded sulfone 5a without any observable racemization in near quantitative yield. Finally, $\beta$-mercaptoester $\mathbf{4 m}$ was reduced to the alcohol in excellent yield, without appreciable loss of enantiopurity. ${ }^{20}$

In summary, we have developed the first organocatalytic enantioselective SMA of alkyl thiols to unactivated $\beta$-substituted- $\alpha, \beta$-unsaturated esters. Impressive reactivity and excellent levels of enantioselectivities were achieved across a range of linear, branched, cyclic alkyl and benzylic thiols, in SMA reactions to various $\beta$-substituted- $\alpha, \beta$-unsaturated esters using a novel bifunctional iminophosphorane catalyst. This work demonstrates that the high reactivity of the BIMP catalysts enables low reactivity electrophiles such as $\beta$-substituted- $\alpha, \beta$ unsaturated esters to undergo highly enantioselective conjugate addition reactions for the first time and thus represents a significant advance in the field. Work to uncover further capabilities of the BIMP catalyst family is ongoing in our laboratories and the results will be disclosed in due course.

\section{Acknowledgements}

We thank the EPSRC (Studentship and Doctoral Training Grant [EP/M50659X/1] to A. J. M. F.), AstraZeneca (Studentship to A. J. M. F.), the SCI (Postgraduate Scholarship to A. J. M. F.) and the China Scholarship Council-University of Oxford Scholarship (Studentship to J. Y.) for funding.

\section{Notes and references}

1 For reviews on organocatalysis, see: (a) P. I. Dalko and L. Moisan, Angew. Chem., Int. Ed., 2004, 43, 5138; (b) A. Berkessel and H. Gröger, Asymmetric Organocatalysis, Wiley VCH, Weinheim, 2005; (c) B. List and J. W. Yang, Science, 2006, 313, 1584; (d) A. Dondoni and A. Massi, Angew. Chem., Int. Ed., 2008, 47, 4638; (e) S. Bertelsen and K. A. Jørgensen, Chem. Soc. Rev., 2009, 38, 2178; $(f)$ C. Palomo, M. Oiarbide and R. López, Chem. Soc. Rev., 2009, 38, 632.

2 (a) S. Matsunaga, T. Kinoshita, S. Okada, S. Harada and M. Shibasaki, J. Am. Chem. Soc., 2004, 126, 7559; (b) F. López, S. R. Harutyunyan, A. Meetsma, A. J. Minnaard and B. L. Feringa, Angew. Chem., Int. Ed., 2005, 44, 2752; (c) C. Pubill-Ulldemolins, A. Bonet, C. Bo, H. Gulyás and E. Fernández, Chem.-Eur. J., 2012, 18, 1121.

$3 \mathrm{~K}$. Tomioka and Y. Nagaoka, Comprehensive Asymmetric Catalysis, ed. E. N. Jacobsen, A. Pfatlz and H. Yamamoto, Springer, New York, 1999, vol. 3.

4 For examples of enantioselective organocatalytic cycloaddition reactions using crotonate and cinnamate esters, see: (a) B. Mathieu, L. de Fays and L. Ghosez, Tetrahedron Lett., 2000, 41, 9561; (b) D. H. Ryu, T. W. Lee and E. J. Corey, J. Am. Chem. Soc., 2002, 124, 9992; (c) T. Gatzenmeier, M. van Gemmeren, Y. Xie, D. Höfler, M. Leutzsch and B. List, Science, 2016, 351, 949.
5 The electrophile-specific reactivity parameters $E$ of trans- $\beta$ nitrostyrenes have been determined to be $-15<E<-12$ : I. Zenz and H. Mayr, J. Org. Chem., 2011, 76, 9370.

6 Preliminary studies indicate the electrophile-specific reactivity parameters $E$ of ethyl cinnamate and ethyl crotonate are in the range of $-25<E<-23$ : H. Mayr, personal communication.

7 For a review on iminium catalysis, see: A. Erkkilä, I. Majander and P. Pihko, Chem. Rev., 2007, 107, 5416.

8 For reviews on organocatalytic conjugate addition reactions, see: (a) J. L. Vicario, D. Badía, L. Carrillo and E. Reyes, Organocatalytic Enantioselective Conjugate Addition Reactions, Royal Society of Chemistry, Cambridge, 2010; (b) S. B. Tsogoeva, Eur. J. Org. Chem., 2007, 1701.

9 The organocatalytic enantioselective conjugate addition of benzyl mercaptan to activated aryl crotonate esters was reported with a $N$-heterocyclic carbene catalyst: P. Yuan, S. Meng, J. Chen and Y. Huang, Synlett, 2016, 27, 1068.

10 To the best of our knowledge, only a single isolated example of a moderately enantioselective organocatalytic Michael addition to ethyl crotonate has been reported, see: X. Dong, X. Fang and C.-J. Wang, Org. Lett., 2011, 13, 4426.

11 For reviews on Brønsted base $\mathrm{H}$-bond donor bifunctional organocatalysts, see: (a) Y. Takemoto, Org. Biomol. Chem., 2005, 3, 4299; (b) S. J. Connon, Chem. Commun., 2008, 2499; (c) T. Marcelli and H. Hiemstra, Synthesis, 2010, 1229.

12 For the use of chiral organosuperbase catalysts to enhance reactivity, see: (a) J. S. Bandar and T. H. Lambert, J. Am. Chem. Soc., 2012, 134, 5552; (b) M. G. Núñez, A. J. M. Farley and D. J. Dixon, J. Am. Chem. Soc., 2013, 135, 16348; (c) T. Takeda and M. Terada, J. Am. Chem. Soc., 2013, 135, 15306; (d) A. M. Goldys, M. G. Núñez and D. J. Dixon, Org. Lett., 2014, 16, 6294; (e) A. J. M. Farley, C. Sandford and D. J. Dixon, J. Am. Chem. Soc., 2015, 137, 15992; (f) G. P. Robertson, A. J. M. Farley and D. J. Dixon, Synlett, 2016, 27, 21; (g) M. A. Horwitz, B. P. Zavesky, J. Martinez-Alvarado and J. S. Johnson, Org. Lett., 2016, 18, 36.

13 For the use of organosuperbases in synthesis, see: (a) T. Ishikawa, Superbases for Organic Synthesis: Guanidines, Amidines, Phosphazenes and Related Organocatalysts, Wiley, New York, 2009; For a review on chiral organosuperbases, see: (b) T. Ishikawa and T. Kumamoto, Synthesis, 2006, 737; (c) D. Leow and C.-H. Tan, Chem.-Asian J., 2009, 4, 488; (d) D. Leow and C.-H. Tan, Synlett, 2010, 1589; (e) T. Ishikawa, Chem. Pharm. Bull., 2010, 58, 1555; $(f)$ X. Fu and C.-H. Tan, Chem. Commun., 2011, 47, 8210; $(g)$ P. Selig, Synthesis, 2013, 45, 703; (h) H. Krawczyk, M. Dzięgielewski, D. Deredas, A. Albrecht and Ł. Albrecht, Chem.-Eur. J., 2015, 21, 10268. For selected examples, see: (i) E. J. Corey and M. J. Grogan, Org. Lett., 1999, 1, 157; (j) T. Ishikawa, Y. Araki, T. Kumamoto, H. Seki, K. Fukuda and T. Isobe, Chem. Commun., 2001, 245; (k) B. M. Nugent, R. A. Yoder and J. N. Johnston, J. Am. Chem. Soc., 2004, 126, 3418; (l) M. Terada, H. Ube and Y. Yaguchi, J. Am. Chem. Soc., 2006, 128, 1454; $(m)$ D. Uraguchi, S. Sakaki and T. Ooi, J. Am. Chem. Soc., 2007, 129, 12392; (n) T. A. Davis, J. C. Wilt and 
J. N. Johnston, J. Am. Chem. Soc., 2010, 132, 2880; (o) Y. Sohtome, B. Shin, N. Horitsugi, R. Takagi, K. Noguchi and K. Nagasawa, Angew. Chem., Int. Ed., 2010, 49, 7299; (p) T. A. Davis and J. N. Johnston, Chem. Sci., 2011, 2, 1076; (q) D. Uraguchi, K. Yoshioka, Y. Ueki and T. Ooi, J. Am. Chem. Soc., 2012, 134, 19370; (r) M. T. Corbett, D. Uraguchi, T. Ooi and J. S. Johnson, Angew. Chem., Int. Ed., 2012, 51, 4685; (s) T. Misaki, N. Jin, K. Kawano and T. Sugimura, Chem. Lett., 2012, 41, 1675; $(t)$ T. E. Shubina, M. Freund, S. Schenker, T. Clark and S. B. Tsogoeva, Beilstein J. Org. Chem., 2012, 8, 1485; (u) J. S. Bandar and T. H. Lambert, J. Am. Chem. Soc., 2013, 135, 11799; (v) J. S. Bandar, A. Barthelme, A. Y. Mazori and T. H. Lambert, Chem. Sci., 2015, 6, 1537; $(w)$ D. Uraguchi, K. Yamada and T. Ooi, Angew. Chem., Int. Ed., 2015, 54, 9954; (x) M. Ișik, M. Y. Unver and C. Tanyeli, J. Org. Chem., 2015, 80, 828; (y) X. Gao, J. Han and L. Wang, Org. Lett., 2015, 17, 4596; (z) J. Chen, S. Meng, L. Wang, H. Tang and Y. Huang, Chem. Sci., 2015, 6, 4184.

14 For a review on asymmetric sulfa-Michael additions, see: $(a)$ D. Enders, K. Lüttgen and A. A. Narine, Synthesis, 2007, 959. For selected examples using metals, see: $(b)$ K. Nishimura, M. Ono, Y. Nagaoka and K. J. Tomioka, J. Am. Chem. Soc., 1997, 119, 12974; (c) S. Kanemasa, Y. Oderaotoshi and E. Wada, J. Am. Chem. Soc., 1999, 121, 8675; (d) K. Nishimura, M. Ono, Y. Nagaoka and K. Tomioka, Angew. Chem., Int. Ed., 2001, 40, 440; (e) Y. Hui, J. Jiang, W. Wang, W. Chen, Y. Cai, L. Lin, X. Liu and X. Feng, Angew. Chem., Int. Ed., 2010, 49, 4290; (f) S. Bonollo, D. Lanari, F. Pizzo and L. Vaccaro, Org. Lett., 2011, 13, 2150; $(g)$ T. Kitanosono, M. Sakai, M. Ueno and S. Kobayashi, Org. Biomol. Chem., 2012, 10, 7134; (h) T. Ogawa, N. Kumagai and M. Shibasaki, Angew. Chem., Int. Ed., 2012, 51, 8551.

15 For a review on organocatalytic asymmetric SMA reactions, see: (a) P. Chauhan, S. Mahajan and D. Enders, Chem. Rev., 2014, 114, 8807. For selected examples, see: (b) H. Hiemstra and H. Wynberg, J. Am. Chem. Soc., 1981, 103, 417; (c) A. Kumar, R. V. Salunkhe, R. A. Rane and S. Y. Dike, J. Chem. Soc., Chem. Commun., 1991, 485; (d)
P. McDaid, Y. Chen and L. Deng, Angew. Chem., Int. Ed., 2002, 41, 338; (e) B.-J. Li, L. Jiang, M. Liu, Y.-C. Chen, L.-S. Ding and Y. Wu, Synlett, 2005, 603; $(f)$ D. Leow, L. Shishi, S. K. Chittimalla, X. Fu and C.-H. Tan, Angew. Chem., Int. Ed., 2008, 47, 5641; (g) Y. Liu, B. Sun, B. Wang, M. Wakem and L. Deng, J. Am. Chem. Soc., 2009, 131, 418; (h) K. L. Kimmel, M. T. Robak and J. A. Ellman, J. Am. Chem. Soc., 2009, 131, 8754; (i) N. K. Rana, S. Selvakumar and V. K. Singh, J. Org. Chem., 2010, 75, 2089; (j) L. Dai, S.-X. Wang and F.-E. Chen, Adv. Synth. Catal., 2010, 352, 2137; (k) N. K. Rana and V. K. Singh, Org. Lett., 2011, 13, 6520; (l) L. Dai, H. Yang and F. Chen, Eur. J. Org. Chem., 2011, 5071; $(m)$ C. Palacio and S. Connon, Chem. Commun., 2012, 48, 2849; (n) D. Uraguchi, N. Kinoshita, D. Nakashima and T. Ooi, Chem. Sci., 2012, 3, 3161; (o) L. Dai, H. Yang, J. Niu and F. Chen, Synlett, 2012, 314; (p) A. C. Breman, J. M. M. Smits, R. de Gelder, J. H. van Maarseveen, S. Ingemann and H. Hiemstra, Synlett, 2012, 23, 2195; (q) X. Fang, J. Li and C.-J. Wang, Org. Lett., 2013, 15, 3448; $(r)$ R. A. Unhale, N. K. Rana and V. K. Singh, Tetrahedron Lett., 2013, 54, 1911; $(s)$ R. Wang, J. Liu and J. Xu, Adv. Synth. Catal., 2014, 357, 159; $(t)$ J. P. Phelan, E. J. Patel and J. A. Ellman, Angew. Chem., Int. Ed., 2014, 53, 11329; (u) N. K. Fu, L. Zhang, S. Z. Luo and J. P. Cheng, Org. Lett., 2014, 16, 4626.

16 F. G. Bordwell and D. L. Hughes, J. Org. Chem., 1982, 47, 3224.

17 For comparison, the $\mathrm{p} K_{\mathrm{a}}$ of thiophenol in DMSO is 10.3. See ref. 16.

18 Bifunctional cinchonine derived bifunctional thiourea catalysts [890044-38-9] were found to be impotent in this transformation. After 7 days under analogous conditions no addition product $4 \mathrm{a}$ was observed by ${ }^{1} \mathrm{H}$ NMR analysis of the crude reaction mixture.

19 The reaction with $\mathrm{PhSH}, \mathbf{2 a}$ and catalyst 1e proceeded with $93 \%$ yield and $66: 34$ er.

20 The PMB thiol can be readily cleaved to afford the free mercaptan, see for example ref. $15 \mathrm{~g}$. 